Later chapters of his book deal with the future measures which will be required for staving off disaster, and the discovery of an ideal method of contraception is the most pressing need of all. All experts on this subject agree that what is required is a preparation which ean be taken by the mouth and which is guaranteed to cause no harm. This pill may work in various ways ; by inhibiting ovulation or the nidation and the development of the fertilized ovum; or by inhibiting spermatogenesis in the male. But there are other links in the chain of fecundation which might be broken artificially and these possibilities are reviewed by the author in an appendix. $\mathrm{He}$ rightly deplores the fact that whereas immense sums of money can easily be raised for research on a cure for cancer, there is little financial support for what is a far more urgent human problem. But Dr. Meier does not despair. He believes that the situation "is such that we must not reasonably expect to find that the first mass manufacture and use of oral contraception will come into being before the 1970-75 period".

Dr. Meier's book is the completest and the best survey of the world population problem which has yet appeared, and it is a work which is indispensable to everybody who is interested in this all-important subject.

KENNETH WALKRR

\section{TEXTILE ENGINEERING}

\section{Textile Engineering Processes}

Edited by Prof. A. H. Nissan. Pp. ix +366 . (London : Butterworths Scientific Publications; New York: Academic Press, Inc., 1959.) 60s. ; 9.25 dollars.

$\mathrm{M}$ ODERN textile industry is becoming increasingly dependent for its future prosperity on the recruitment of graduate scientists and engineers, so that it can derive the greatest benefit from modern scientific discoveries arising from research and development into textile materials and processing. Several books are available in which the chemical and physical aspects of textiles are discussed, but little has been written with the needs of engineers in mind. Such a book has become more necessary now that the Institution of Mechanical Engineers has created an option in textile engineering in the examination for the associate membership.

The present volume is intended to give to engineers a concise account of the processes involved in converting fibres into fabrics, special attention being paid to the mechanical aspects of the subject. Difficulties of writing such a work are considerable, for the textile industry is divided into many specialized sections. Prof. Nissan has, however, been successful in obtaining several collaborators, each of whom is a specialist in his own field. It is impossible to survey all the important aspects of textiles in the space available, and consequently attention has been limited to the following topics: physical properties of textile fibres, yarns and fabrics; the principles and techniques of yarn and cloth production, including knitting; wet finishing, and dyeing and printing machinery. Rather more specialized accounts of the important topics of drying, humidity control, and automatic control complete the volume. Each chapter is in effect an essay on a particular aspect of textile processing. The various authors appear to have interpreted their terms of reference rather differently, but all have given clear and concise accounts of their subject. Some have treated topics in a general descriptive way while others have chosen to discuss specific aspects in greater detail. These differences are offset to some extent by the suggestions for further reading given at the end of each chapter.

The book is a welcome addition to the literature on textiles. As an introduction to the subject, engineers and physicists will find it useful particularly in its treatment of yarn and cloth manufacture, while those already acquainted with textiles will appreciate the parts dealing with more specialized topies. It is unfortunate that the book is so expensive; if the present trend in the price of text-books continues, students will soon be unable to buy them.

C. S. WhEWELL

\section{BONDS BETWEEN RUBBER AND METAL}

Rubber to Metal Bonding

By Dr. S. Buchan. Second edition, revised. Pp. xiv + $300+35$ plates. (London: Crosby Lockwood and Son, Ltd., 1959.) 42s. net.

THE first edition of Dr. Buchan's book, published in 1948, described the technological situation as it existed after the intense effort of the War. Most of it was concerned with the very successful brass plating method of achieving bonds between rubber and metal, and Buchan's own work, aimed at understanding the mechanism as well as rigidly controlling the product, was naturally described in great detail. The evidence he presented pointed strongly to a sulphur bond between the copper of $\alpha$-brass and the rubber. A further ten years have passed; but our knowledge remains where it was, and one is led to question the usefulness of printing a second edition. True, the revision has been thorough, as all chapters bear evidence by the addition of more recent information from the literature and from the author's experience with the newer chemical bonding agents, but the scientific situation remains unaltered and the chapter on the nature of the rubber-to-metal bond, although rewritten, is weak.

Technologically, the book is still comprehensive and indispensable because it gives practical details, formulæ and, most important, the test results obtained. Some processes, such as latex-blood. albumen, are now obsolete and could have been deleted, while the space devoted to the brass-plating method, although valuable, would give the newcomer a false idea of its present popularity. The reviewer knows of no new plants for producing bonded rubbers by this method, while some have actually closed down or retracted in scale. The new chapters on chemical methods added to the second edition do not make this point nor do they give any indication of comparative processing or capital costs. Is it just this factor that has told against the brass-plating process ?

There are a fow minor blemishes for which the publisher must be blamed. A large proportion, in fact nearly all, of the graphs shown are not professionally drawn, and the lettering is bad. 'm.m.' for ' $\mathrm{mm}$ ' is irritating as well as wrong. 'G.R.S.' for 'GR-S' is inelegant and in any event it was superseded during 1957 by 'SBR', which is now universally used as the abbreviation for butadiene-styrene rubber.

W. C. WAKE 